\title{
RECYCLING OF OIL FLY ASH IN THE ADSORPTION OF DYES FROM INDUSTRIAL WASTEWATER
}

\begin{abstract}
The use of oil fly ash after the recovery of heavy valuable metals was investigated. More specifically, its use, as an adsorbent of dyes from industrial wastewater, was evaluated. Methylene blue was used as a model compound to study the adsorption capacity of the proposed carbonaceous residue from metal recovery treatments. The effects of contact time, initial dye concentration, and absorbent dose were investigated. The maximum amount of dye was adsorbed after one hour. Moreover, 1-3 g of residues were necessary for the removal of 200-1000 mg dm $\mathrm{m}^{-3}$ from $0.050 \mathrm{dm}^{3}$ of contacted solution. The Langmuir isotherm model was in good agreement with the adsorption equilibrium data, indicating a maximum monolayer saturation capacity of approximately $40 \mathrm{mg} / \mathrm{g}$ at $25{ }^{\circ} \mathrm{C}$. High abatement efficiencies (up to $99 \%$ ) were obtained, and the adsorbed dye was released almost immediately by re-contacting with water. The adsorption capacity was at least four times lower than that of commercially available active carbon. The double treatment of oil fly ash with deionised water and hydrochloric acid allows for the extraction of over $85 \%$ of the vanadium, iron, and nickel content in the ash. However, the negligible or zero cost of solid residues, otherwise disposed in landfills, indicates their potential as a valid alternative. The use of oil fly ash for both recovery of heavy valuable metals and the subsequent removal of dyes from wastewater suggest a zero-waste process.
\end{abstract}

Keywords: oil fly ash, adsorption, methylene blue, low-cost adsorbent, waste management

\section{Introduction}

Oil fly ash is of great environmental concern. It has little or no economic value and, if no other use is possible, it must be disposed of or landfilled. The current waste management regulations indicate that landfill disposal is to be used only as a last resort, as it requires an increasing number of disposal sites and involves costs that can be significant, especially when the waste is hazardous and demands inertisation treatments. The conversion of waste into high added-value materials can fulfil economic and environmental requirements of current legislation, which establishes a hierarchy of preferences for waste management, where recycling and reuse are of fundamental importance, as well as efforts to prevent waste production [1].

In the last few decades, various investigations and analyses suggested the reutilisation and reduction of the amount of oil fly ash [2-5]. Most researches have been focusing on the industrial applications of coal fly ash [6,7] and its safe disposal [8]. In this context, published studies are more focused on valuable metals extraction [9-12] and surface characterisation $[13,14]$. Oil fly ash is a special type of hazardous waste and is produced by

\footnotetext{
${ }^{1}$ Dipartimento di Ingegneria, Università degli Studi di Messina, Contrada di Dio, Messina, 98166, Italy, phone +390906765598

*Corresponding author: Patrizia.Primerano@unime.it
} 
oil fuelled power plants. It contains hazardous metals (mainly vanadium and nickel), mostly in the form of soluble bisulphates/sulphates, which are partially released immediately after contact with water [15]. For this reason, before landfilling, the waste must be appropriately treated to reduce the concentrations of these metals to levels below the legal limits for disposal of hazardous waste. This treatment adds further costs to the waste transport, which could be avoided if sustainable alternatives for its use were available.

Primerano et al. [11] developed high-performance technologies for the recovery of high added-value vanadium and nickel compounds (vanadium pentoxide, vanadium and iron oxide, and nickel and iron oxide) from oil fly ash. The application of these technologies to the ash produced by Italian fuel oil power plants could meet the demand for vanadium and nickel and reduced the need for hazardous waste disposal. In addition, there would be a consequent reduction of costs and the provision of job opportunities. Although in the last decade the production of oil fly ash in Italy decreased (from approximately $40,000 \mathrm{Mg}$ in 2000 to approximately 7,000 Mg in 2009), it cannot be dismissed. Fuel oil was the most used fossil energy source until a few decades ago. However, it has been less used in recent years and became the third most used source (after natural gas and coal). Nevertheless, fuel oil is expected to be used for a long time in thermoelectric power plants.

After the treatments for the recovery of vanadium and nickel from oil fly ash, a large quantity of unburned carbon remains. This residue is usually disposed of in landfills or incinerated, but these have related drawbacks [16]. Therefore, the exploitation of these carbon residues as such is desirable to fully recycle the oil fly ash. Their use as adsorbents could be implemented for this purpose and is in line with recent research that seeks alternatives to activated carbon, which is an expensive adsorbent. Currently, the main studies suggest the production of adsorbents from natural clay minerals [17-20] agricultural waste [21-27] and industrial activities [28-36]. In this scenario, the use of carbonaceous residue (from metal recovery treatment) as adsorbent of dyes from coloured wastewater of textiles manufacturing has been individuated.

In this paper, the absorption capacity of this carbonaceous residue towards methylene blue (MB) was investigated. $\mathrm{MB}$ is a commonly employed dye in textile industries, mainly for silk and cotton colouring. It is usually used as a model compound in adsorption studies due to its well-known adsorption capacity onto solid materials [34, 37-45]. The salient novelty of this work is to enable the use of a residue from a metal recovery treatment as an adsorbent. This possibility is an alternative to the oil fly ash landfill disposal, and it completes the recovery cycle of its valuable metal components. Therefore, the global process aims at minimising waste and fully utilizing the resources [46-49]. These adsorption capacities are generally conferred to carbonaceous residues through thermal or chemical treatments [2], whereas for other types of residues from waste (i.e. biomass or agriculture), a carbonization treatment and subsequent activation is necessary $[50,51]$.

The paper is structured as follows. The following section reports the experimental work, which includes the pre-treatments of oil fly ash samples, the treatments for the preparation of the adsorbents (which are a by-product of the metal recovery process), the adsorption studies, and finally the analyses and characterisation of samples and residues. Then a section providing the results and the related discussion is given, and the final section reports some conclusive remarks. The whole process presented in this paper, including the recovery of valuable metals from oil fly ash and the employment of the residue as it is without further treatments for the absorption of dyes, was properly planned to offer the following environmental advantages: (i) recycling of hazardous wastes into compounds 
with high value-added, and (ii) decolouration of industrial wastewater using an adsorbent with low cost.

\section{Materials and methods}

\section{Oil fly ash samples}

Three samples of oil fly ash were collected from the electrostatic precipitators of two Sicilian oil-fired plants, i.e. Termini Imerese (TI) and San Filippo del Mela (SFM). They were collected over ten years (1994-2005) and labelled according to their provenance (TI, SFM320, and SFM160, where the number 320 and 160 refers to the unit inside the plant SFM). Two aliquots of each sample were dried at $110^{\circ} \mathrm{C}$ for 2 hours before the analysis to determine unburnt carbon, vanadium, iron, nickel, magnesium, and sulphur.

\section{Oil fly ash samples}

Aliquots of the dried samples of oil fly ash were mixed with deionised water, resulting in $0.005 \mathrm{dm}^{3} / \mathrm{g}$. The aliquots were kept under stirring conditions for 10 minutes at room temperature. After the separation from the liquid phase by filtration, the solid phase was stirred for one hour at $90{ }^{\circ} \mathrm{C}$ with an $\mathrm{HCl}$ aqueous solutions $2 \mathrm{M}(1 \mathrm{~g}$ of oil fly ash has been mixed $0.005 \mathrm{dm}^{3}$ ). After that, this solution was filtered and washed with deionised water until a neutral $\mathrm{pH}$ was reached. The obtained solid residues will henceforth be referred to as washed ash (WA), which were labelled WA-TI, WA-SFM320, and WA-SFM160. They were dried at $110{ }^{\circ} \mathrm{C}$ until they reached a constant weight. WA is the adsorbent whose surface was characterised as shown below.

\section{Preparation of aqueous dye solutions}

MB (molecular weight of $373.9 \mathrm{~g} / \mathrm{mol}$ ) was used as the dye for the adsorption tests. It was supplied by Sigma Aldrich. A stock solution of $1000 \mathrm{mg} / \mathrm{dm}^{3}$ of MB was prepared by dissolving $1 \mathrm{~g}$ of $\mathrm{MB}$ in $1 \mathrm{dm}^{3}$ of distilled water. Experimental solutions with the desired concentrations were obtained by successive dilutions.

\section{Adsorption studies}

To study the adsorption properties, 1-3 g aliquots of each sample of WA were mixed in a beaker glass with $0.050 \mathrm{dm}^{3}$ of $\mathrm{MB}$ aqueous solution, resulting in a concentration ranging from 200 to $1000 \mathrm{mg} / \mathrm{dm}^{3}$. The sample was constantly stirred and kept at room temperature for up to $24 \mathrm{~h}$. At pre-established intervals, $0.005 \mathrm{dm}^{3}$ aliquots of slurry were collected, filtered with a 0.45 -micron Millipore filter, and analysed to determine the MB. The solid phases obtained from the previous filtration were re-contacted with distilled water, and the $\mathrm{MB}$ in the liquid phase was determined.

To determine the uptake capacity of dye by the adsorbent at equilibrium, $q_{e}$ and at any time, $q_{t}$ from the aqueous solutions of $\mathrm{MB}$, the following equations were used [52]:

$$
\begin{aligned}
& q_{e}=\left(C_{o}-C_{e}\right) \cdot V / S \\
& q_{t}=\left(C_{o}-C_{t}\right) \cdot V / S
\end{aligned}
$$

where $q_{e}$ is the amount of dye fixed per unit of adsorbent mass at equilibrium $[\mathrm{mg} / \mathrm{g}] ; q_{t}$ is the amount of dye fixed per unit of adsorbent mass $[\mathrm{mg} / \mathrm{g}]$ at any time $t ; C_{o}, C_{e}$, and $C_{t}$ are the concentration of the dye in the liquid phase $\left[\mathrm{mg} / \mathrm{dm}^{3}\right]$ at the beginning, equilibrium, and 
any time $t$, respectively; $V$ is the volume of the dye solution $\left[\mathrm{dm}^{3}\right]$; and $S$ is the amount of adsorbent used $[\mathrm{g}]$.

The percentage of dye removal, $q_{r}[\%]$, is given by:

$$
q_{r}=\left(C_{o}-C_{e}\right) / C_{o} \cdot 100 \quad[\%]
$$

Three factors varied during the experiments, i.e. $C_{o}$ - initial dye concentration in the liquid phase, $t$ - contact time, and $S$ - the absorbent dose.

The concentration of $\mathrm{MB}$ in the filtrates after and before adsorption were determined by using a UV/VIS/NIR spectrophotometer (Perkin Elmer Lambda 750) at $664 \mathrm{~nm}$. The calibration curve method was used to determine the concentration of MB. The curve was constructed with respect to the concentration range $0.5-2.5 \mathrm{mg} / \mathrm{dm}^{3}\left(R^{2}=0.997\right)$, and the detection limit was $0.05 \mathrm{mg} / \mathrm{dm}^{3}$.

\section{Characterisation}

The samples of ash and WA were characterised, to determine: (a) the total concentration of unburnt carbon, vanadium, iron, nickel, magnesium, and sulphur; (b) the pore size and specific Brunauer-Emmett-Teller (BET) surface area.

The analyses for the chemical characterisation were made as indicated in [15].

The analyses to determine the pore size and the specific BET surface area were performed for the original samples and the solid phases obtained from the leaching procedures (WA) through the adsorption of $\mathrm{N}_{2}$ at $-196{ }^{\circ} \mathrm{C}$ (Micromeritics ASAP 2010). The surface area of the sample was determined by using the BET equation.

\section{Results and discussion}

\section{Effect of contact time on the adsorption equilibrium}

The batch adsorption tests show that equilibrium conditions were reached within one hour of contact. The results show more than $99 \%$ of MB abatement efficiency by using the WA-TI sample and less than $50 \%$ by using the other two samples (WA-SFM320 and WA-SFM160). These removal efficiencies refer to the use of $1 \mathrm{~g}$ samples. The MB solutions, which were strongly coloured before the contact with the carbonaceous residues, became almost colourless after the contact with the WA-TI sample and remained strongly coloured in the other two cases.

Figure 1 shows the effect of contact time on the MB removal by the samples of WA $(1 \mathrm{~g})$ at room temperature $\left(25^{\circ} \mathrm{C}\right)$. It was observed that the adsorption process is fast in the initial stage of the contact period $(\approx 1$ hour $)$, but it gradually slows down until it reaches equilibrium. The fast adsorption in the initial stage was due to the availability of many surface sites for the process. Therefore, to assess the decolourising efficiency of each WA sample with different concentrations of MB solution, the contact time was set to one hour. 


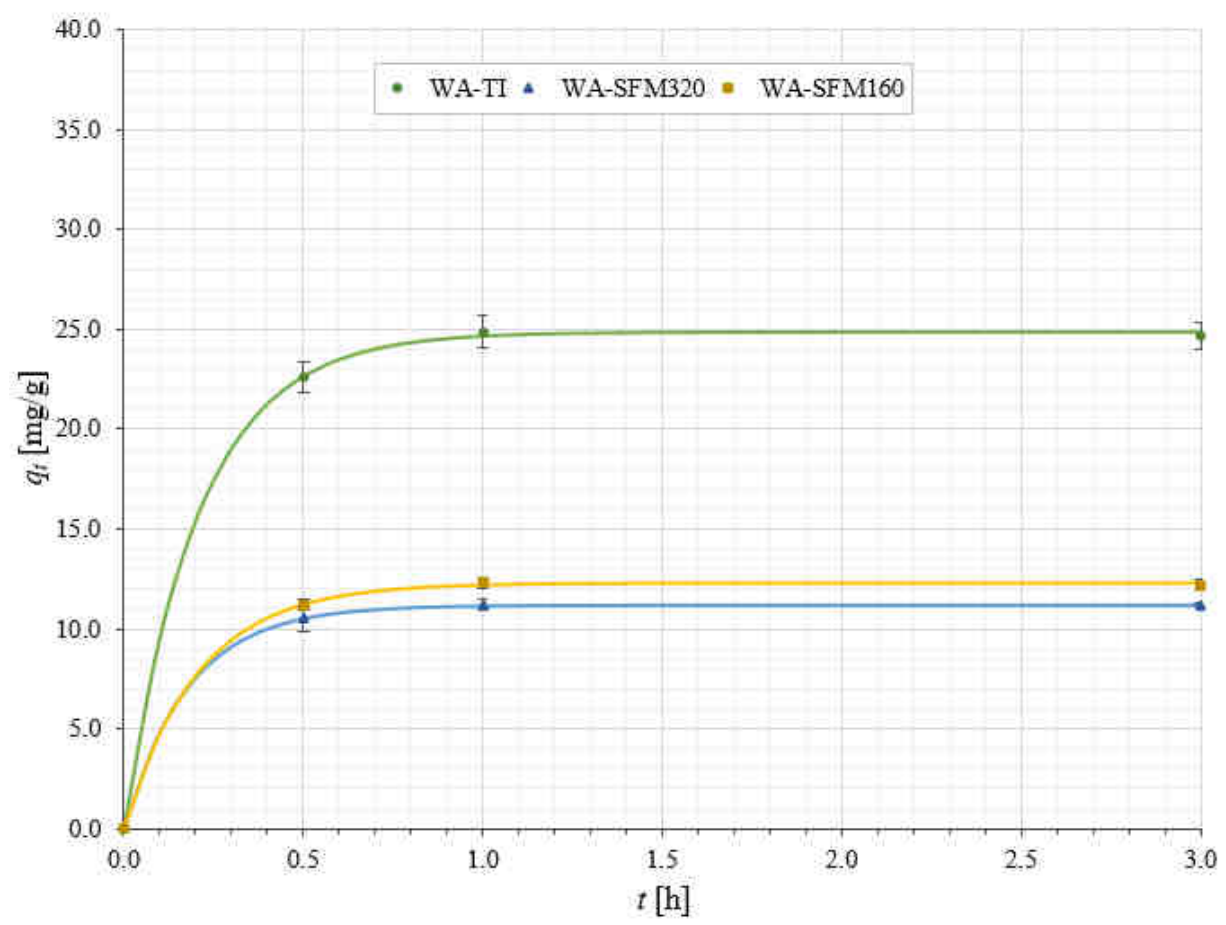

Fig. 1. Effect of contact time on dye adsorption: quantities of $\mathrm{MB}$ adsorbed by $1 \mathrm{~g}$ of oil fly ash residues (WA) over 0.5 to $24 \mathrm{~h}\left(C_{o}=500 \mathrm{mg} / \mathrm{dm}^{3} ; \mathrm{S}=1 \mathrm{~g} ; V_{M B}=0.050 \mathrm{dm}^{3} ; T=\right.$ room temperature)

\section{Effect of initial dye concentration on the adsorption equilibrium}

The effect of initial dye concentration on the removal efficiency of each WA sample (1 g) was assessed by varying the concentration of the MB solution from 200 to $1000 \mathrm{mg} \mathrm{dm}^{-3}$, after setting the contact time to one hour. The results are shown in Figure 2. As the initial dye concentration increases, the $\mathrm{MB}$ uptake at equilibrium, due to the adsorption on WA-TI, WA-SFM320, and WA-SFM320, increases respectively from 10.0 to $40.1 \mathrm{mg} / \mathrm{g}, 6.5$ to $17.5 \mathrm{mg} / \mathrm{g}$, and 5.7 to $12.9 \mathrm{mg} / \mathrm{g}$. The higher the initial dye concentration, the higher the driving force provided to overcome the mass transfer resistance of the dye from the aqueous to the solid phase. Moreover, at higher initial dye concentration, the number of molecules competing for the available sites on the surface of carbonaceous residue is high, resulting in a higher adsorption capacity. Figure 3 shows the efficiency of dye removal as a function of initial MB concentration. 


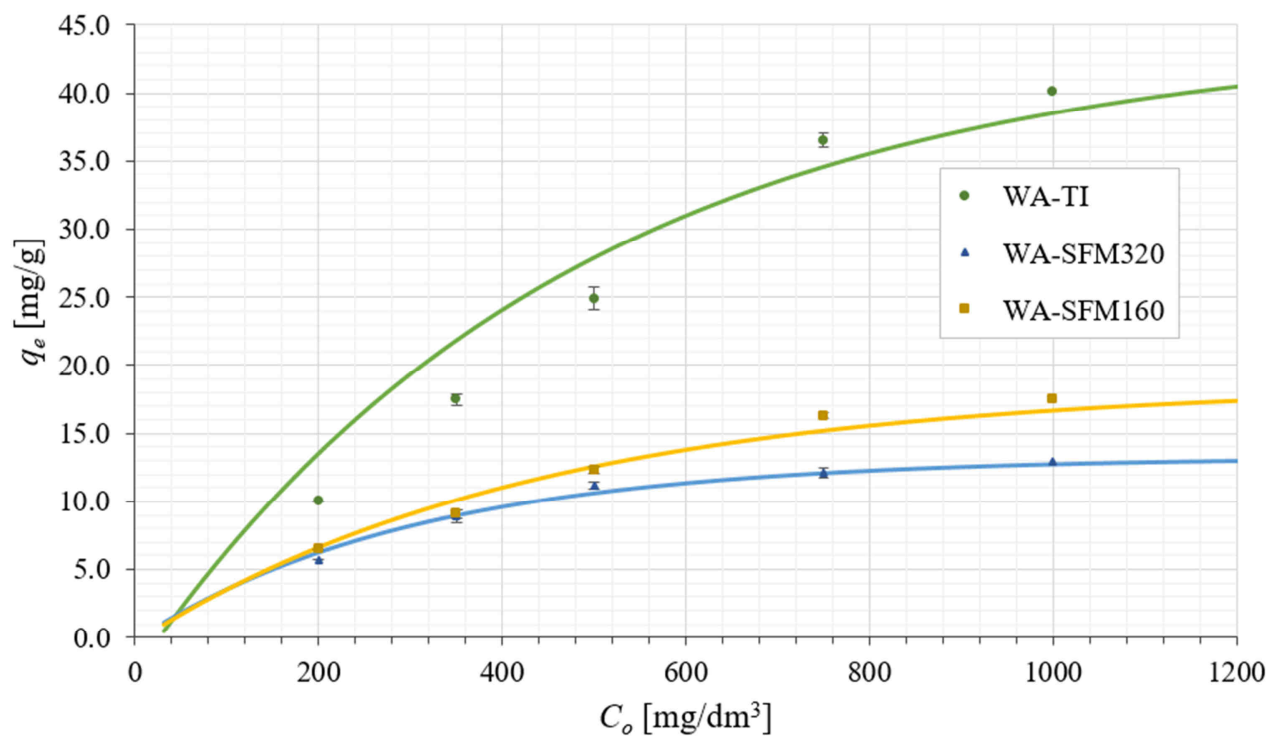

Fig. 2. Effect of initial dye concentration on dye adsorption: quantities of MB adsorbed by $1 \mathrm{~g}$ of oil fly ash residues (WA) with initial MB solution between 200 and $1000 \mathrm{mg} / \mathrm{dm}^{3}(t=1 \mathrm{~h}$; $V_{M B}=0.050 \mathrm{dm}^{3} ; T=$ room temperature)

- WA-TI - WA-SFM320 WA SFM160

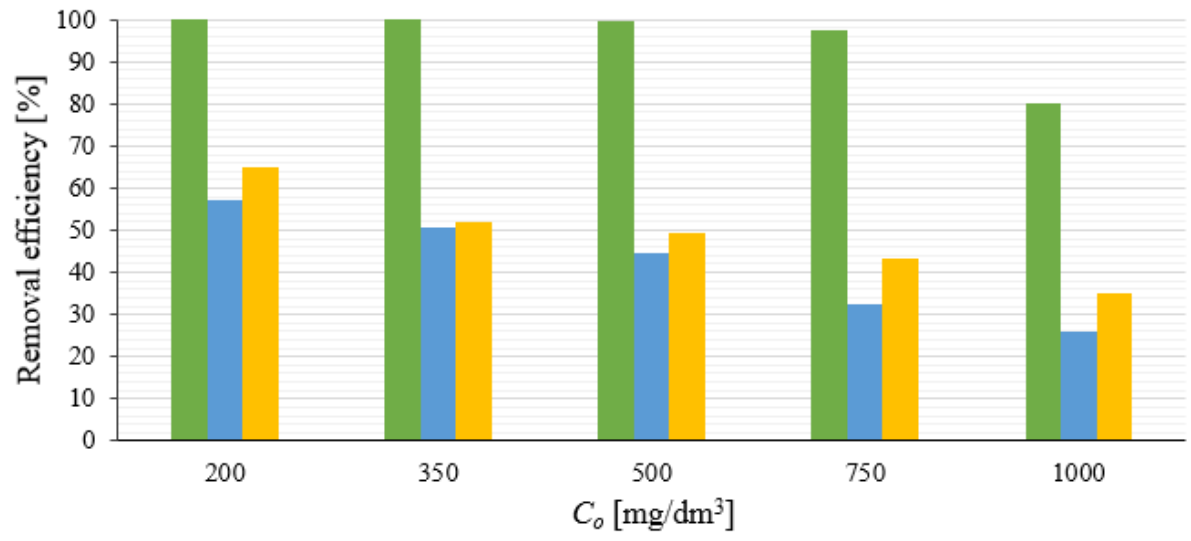

Fig. 3. Effect of initial dye concentration on removal efficiency $\left(t=1 \mathrm{~h} ; S=1 \mathrm{~g} ; V_{M B}=0.050 \mathrm{dm}^{3}\right.$; $T=$ room temperature)

\section{Effect of the adsorbent dose on the adsorption equilibrium}

Given the limited adsorption efficiency of WA-SFM compared to WA-TI, the effect of adsorbent mass on the decolourising efficiency was assessed only for the WA-SFM320 and 
WA-SFM160. The analysis was performed by varying the quantity of solids from 1 to $3 \mathrm{~g}$. Different concentrations of MB solution (from 200 to $1000 \mathrm{mg} / \mathrm{dm}^{3}$ ) were tested after setting the contact time to one hour. The obtained results are shown in Figure $4 \mathrm{a}$ and $\mathrm{b}$.

a)

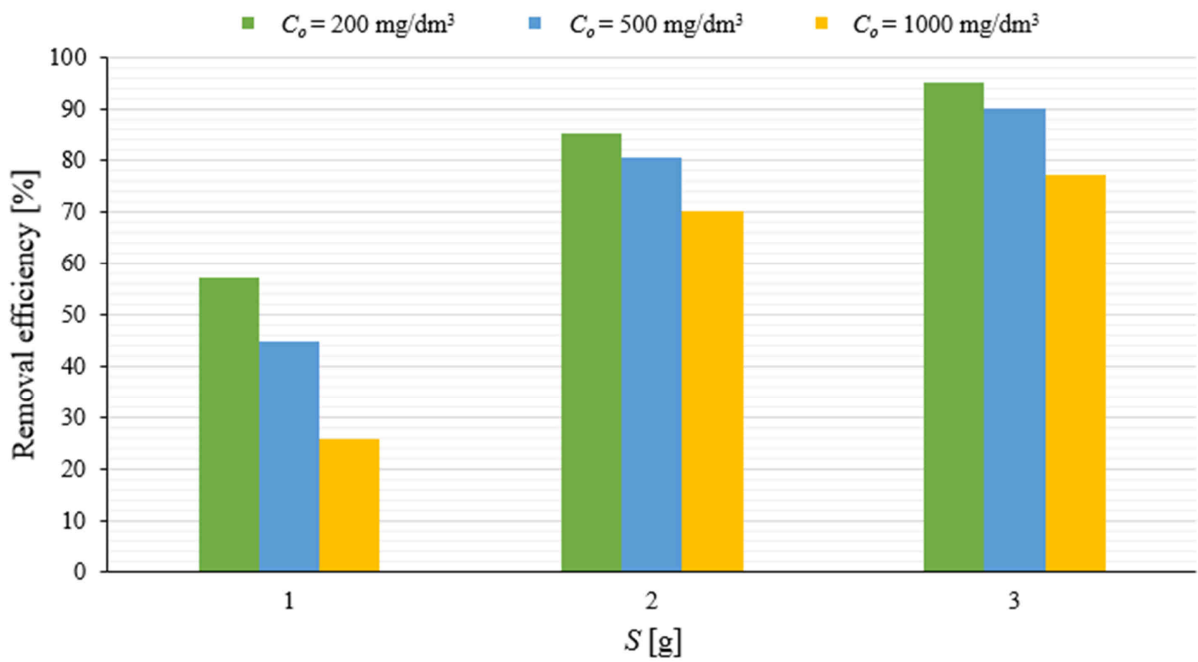

b)

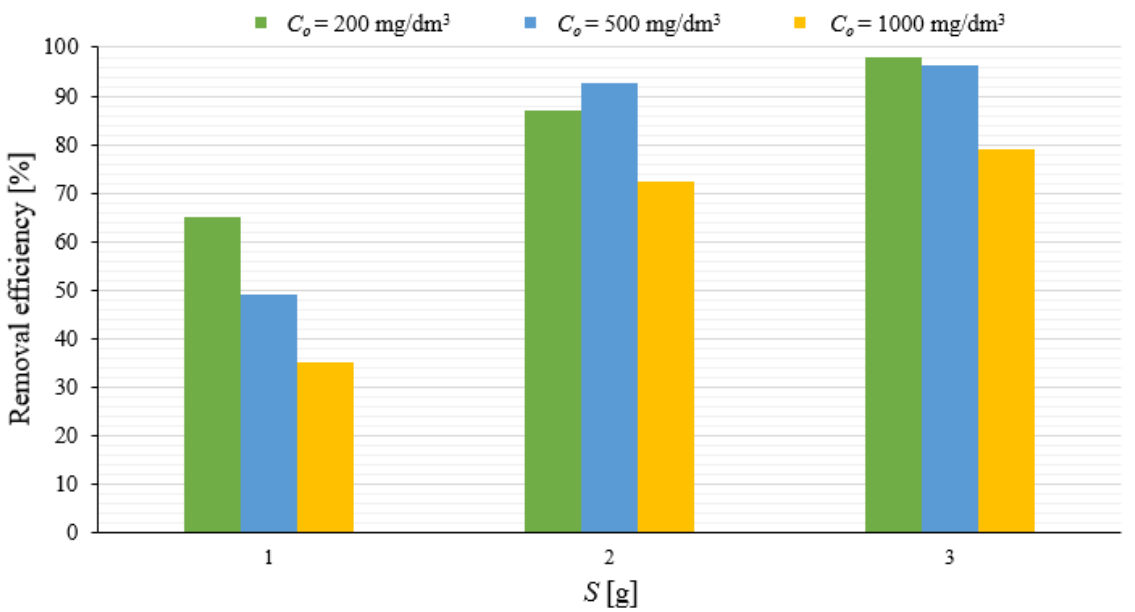

Fig. 4. Effect of adsorbent dose on dye adsorption: removal efficiency of: a) WA-SFM320 oil fly ash residue and b) WA-SFM160 oil fly ash residue, by varying the adsorbent mass from 1 to $3 \mathrm{~g}$ and the initial concentration of MB solution from 200 to $1000 \mathrm{mg} / \mathrm{dm}^{3}\left(t=1 \mathrm{~h} ; V_{M B}=0.050 \mathrm{dm}^{3}\right.$; $T=$ room temperature)

\section{Adsorption modelling}

Batch experiments were used to derive the capacity of the adsorbent to remove the dye, which can be described by isotherms [53-56]. In this study, the experimental equilibrium 
data for the MB adsorption by the WA samples were modelled and compared using two isotherm models, namely the Langmuir and Freundlich isotherms.

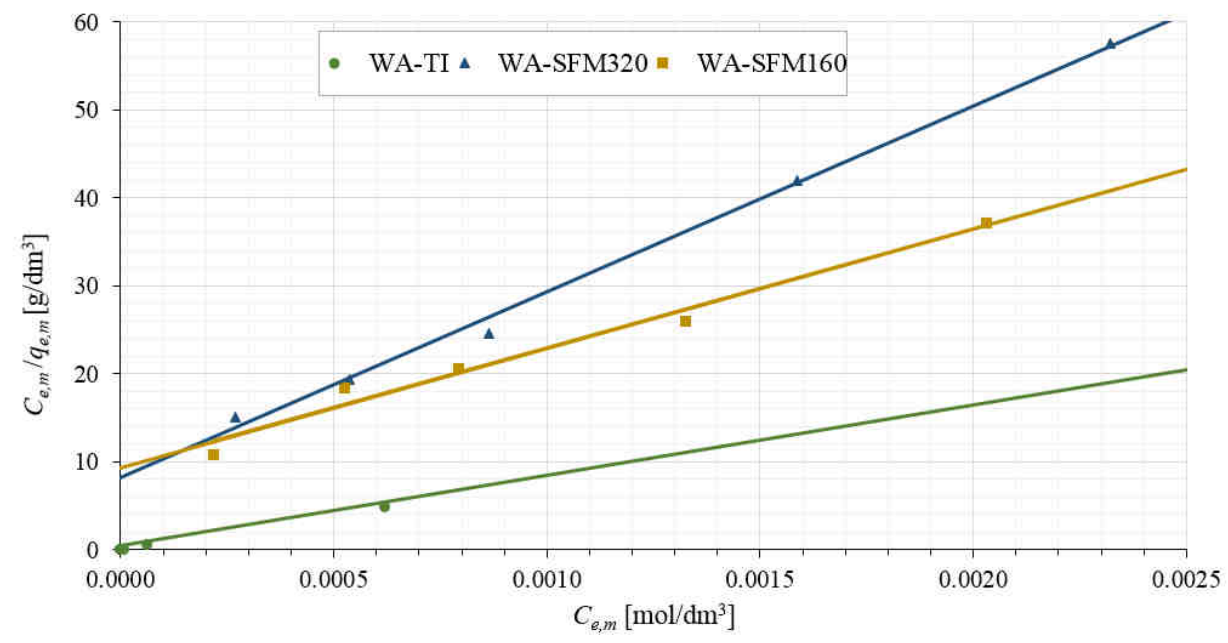

Fig. 5. Langmuir isotherm plot for the adsorption of MB on different WA samples at $25^{\circ} \mathrm{C}$

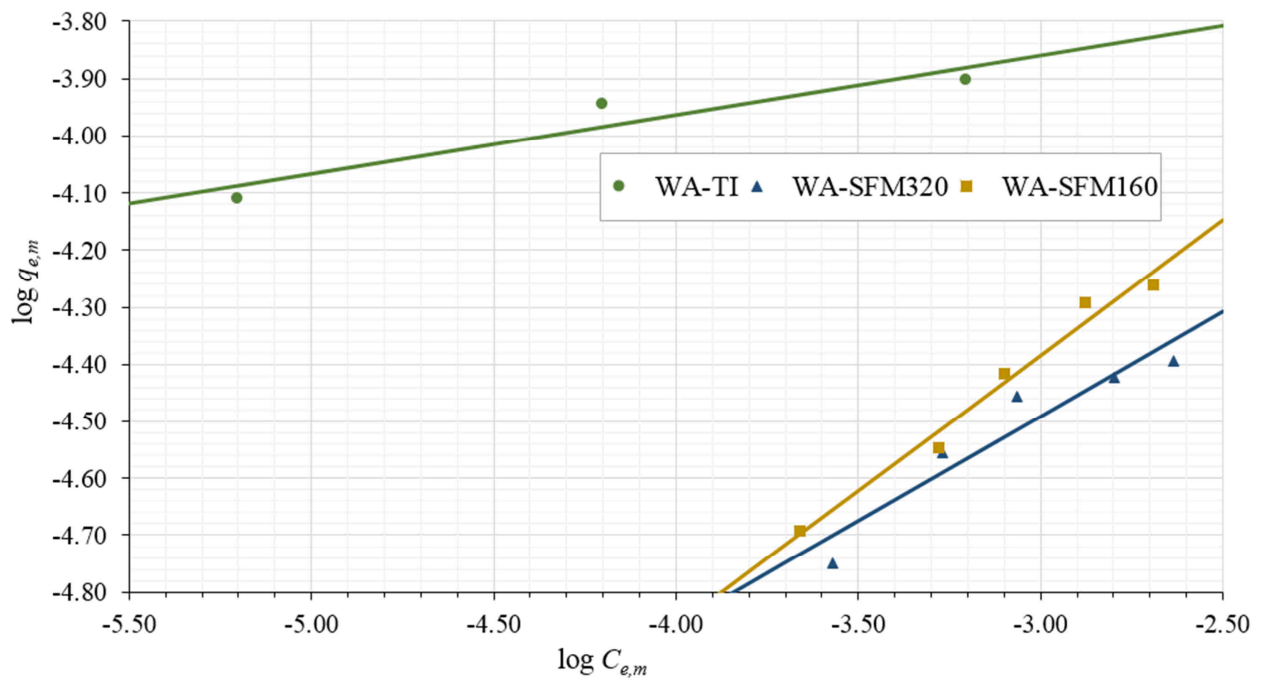

Fig. 6. Freundlich isotherm plot for the adsorption of MB on different WA samples at $25^{\circ} \mathrm{C}$

The Langmuir model considers that adsorption sites are homogeneous, and a monolayer dye coverage is assumed when the saturation value is reached [57]. Therefore, no further adsorption can occur when these sites are occupied by the dye molecules, and the saturation or monolayer capacity is a characteristic parameter for the phenomenon. The adsorption is expressed by the following linear equation: 


$$
\frac{C_{e, m}}{q_{e}}=\frac{1}{q_{\max } K_{L}}+\frac{C_{e, m}}{q_{\max }}
$$

where $C_{e, m}$ is the dye concentration in the solution at equilibrium $\left[\mathrm{mol} / \mathrm{dm}^{3}\right] ; q_{e, m}$ is the amount of dye fixed on the adsorbent at equilibrium $[\mathrm{mol} / \mathrm{g}] ; q_{\max }$ is the monolayer capacity of the adsorbent [mol/g]; and $K_{L}$ is the Langmuir adsorption constant $\left[\mathrm{dm}^{3} / \mathrm{mol}\right]$.

The Freundlich model considers the adsorbent surface to be heterogeneous, and its heterogeneity is expressed by the factor $1 / n[57,58]$. The phenomenon is not limited to the formation of the monolayer dye coverage. In this case, the saturation is expressed by an equation that can be converted into the following linear form:

$$
\log q_{e, m}=\log K_{F}+1 / n \cdot \log C_{e, m}
$$

where $K_{F}$ is the Freundlich adsorption constant $\left[\mathrm{mol} / \mathrm{g} \cdot\left(\mathrm{dm}^{3} \mathrm{~mol}^{-1}\right)^{1 / n}\right]$; and $1 / n$ is the heterogeneity factor [-].

The Langmuir isotherm is represented by the plot $C_{e, m} / q_{e, m}$ vs. $C_{e, m}$, shown in Figure 5, which is a line with a slope $1 / q_{\max }$ and intercept $1 /\left(q_{\max } \cdot K_{L}\right)$. The Freundlich isotherm is represented by the plot $\log q_{e, m}$ vs. $\log C_{e, m}$, given in Figure 6, which is a line with a slope of $1 / n$ and intercept $K_{F}$.

Isotherm parameters for MB removal by using different samples of WA $\left(T=25^{\circ} \mathrm{C}\right)$

\begin{tabular}{|c|c|c|c|c|c|c|}
\hline \multicolumn{2}{|c|}{ Experimental data } & \multicolumn{5}{|c|}{ Results } \\
\hline $\begin{array}{c}C_{o} \\
{\left[\mathrm{~g} / \mathrm{dm}^{3}\right]}\end{array}$ & $\begin{array}{c}q_{e} \\
{[\mathrm{mg} / \mathrm{g}]}\end{array}$ & Sample & Model & Parameter 1 & Parameter 2 & $R^{2}$ \\
\hline 0 & 0 & \multirow{6}{*}{ WA-TI } & \multirow{3}{*}{ Langmuir } & \multirow{3}{*}{$q_{\max }=39.93 \mathrm{mg} / \mathrm{g}$} & \multirow{3}{*}{$K_{L}=5.02 \cdot 10^{-2} \mathrm{dm}^{3} / \mathrm{mg}$} & \multirow{3}{*}{0.9962} \\
\hline 0.2 & 10 & & & & & \\
\hline 0.35 & 17.5 & & & & & \\
\hline 0.5 & 24.9 & & \multirow{3}{*}{ Freundlich } & \multirow{3}{*}{$1 / n=0.10$} & \multirow{3}{*}{$\begin{array}{c}K_{F}=2.83 \cdot 10^{-4} \\
\left(\mathrm{~mol} \mathrm{~g}^{-1}\right)\left(\mathrm{dm}^{3} \mathrm{~mol}^{-1}\right)^{1 / n}\end{array}$} & \multirow{3}{*}{0.9444} \\
\hline 0.75 & 36.5 & & & & & \\
\hline 1 & 40.1 & & & & & \\
\hline 0 & 0 & \multirow{6}{*}{ WA-SFM160 } & \multirow{3}{*}{ Langmuir } & \multirow{3}{*}{$q_{\max }=15.13 \mathrm{mg} / \mathrm{g}$} & \multirow{3}{*}{$K_{L}=4.53 \cdot 10^{-3} \mathrm{dm}^{3} / \mathrm{mg}$} & \multirow{3}{*}{0.9981} \\
\hline 0.2 & 6.5 & & & & & \\
\hline 0.35 & 9.1 & & & & & \\
\hline 0.5 & 12.3 & & \multirow{3}{*}{ Freundlich } & \multirow{3}{*}{$1 / n=0.37$} & \multirow{3}{*}{$\begin{array}{c}K_{F}=2.60 \cdot 10^{3} \\
\left(\mathrm{~mol} \mathrm{~g}^{-1}\right)\left(\mathrm{dm}^{3} \mathrm{~mol}^{-1}\right)^{1 / n}\end{array}$} & \multirow{3}{*}{0.9479} \\
\hline 0.75 & 16.3 & & & & & \\
\hline 1 & 17.5 & & & & & \\
\hline 0 & 0 & \multirow{6}{*}{ WA-SFM320 } & \multirow{3}{*}{ Langmuir } & \multirow{3}{*}{$q_{\max }=26.61 \mathrm{mg} / \mathrm{g}$} & \multirow{3}{*}{$K_{L}=8.13 \cdot 10^{-3} \mathrm{dm}^{3} / \mathrm{mg}$} & \multirow{3}{*}{0.9890} \\
\hline 0.2 & 5.7 & & & & & \\
\hline 0.35 & 8.9 & & & & & \\
\hline 0.5 & 11.2 & & \multirow{3}{*}{ Freundlich } & \multirow{3}{*}{$1 / n=0.47$} & \multirow{3}{*}{$\begin{array}{c}K_{F}=1.45 \cdot 10^{3} \\
(\mathrm{~mol} / \mathrm{g})\left(\mathrm{dm}^{3} / \mathrm{mol}\right)^{1 / \mathrm{n}}\end{array}$} & \multirow{3}{*}{0.9890} \\
\hline 0.75 & 12.1 & & & & & \\
\hline 1 & 12.9 & & & & & \\
\hline
\end{tabular}

Table 1

The results of the modelling were compared by referring to the adsorption parameters of the MB listed in Table 1 . The highest correlation coefficients $\left(R^{2}\right)$ are approximately 0.99 and are associated with the Langmuir model. Moreover, the modelling through this isotherm was in good agreement with previous studies related to MB adsorption on coal fly ash [59] and on bagasse fly ash [60]. The correlation coefficient for the Freundlich model was 0.98 for the WA-SFM160 sample and 0.94 for the other two cases. Therefore, this model does not present the best fitting data. Consequently, the MB adsorption onto WA 
cannot be considered a multilayer, and the surface of the adsorbent is likely composed of homogeneous adsorption sites. This can also be discussed based on the adsorption constants, i.e. the Freundlich constant $\left(K_{F}\right)$ for MB dye is very low, whereas the Langmuir constants $\left(K_{L}\right)$ are high. A good agreement is observed between the $q_{\max }$ predicted by the Langmuir model and that obtained from the experimental investigation.

\section{Characterisation}

The elementary chemical composition of the oil fly ash, including the main components, is given in Table 2. In addition to the unburnt carbon, the oil fly ash mainly contains metal elements, which are characteristically present in the starting oil and in the additives (e.g. Mg). The only identified non-metal element was sulphur(VI) [61].

Elementary chemical composition of oil fly ashes (weighted percentage of the dried sample $\left[\%_{\mathrm{w}}\right]^{*}$ )

\begin{tabular}{|c|c|c|c|c|c|c|}
\hline \multirow{2}{*}{ Sample } & $\mathbf{C}_{\text {unburnt }}$ & $\mathbf{V}$ & $\mathbf{F e}$ & $\mathbf{N i}$ & $\mathbf{S}$ & $\mathbf{M g}$ \\
\cline { 2 - 7 } & {$\left[\boldsymbol{\%}_{\mathrm{w}}\right]$} & {$\left[\boldsymbol{\%}_{\mathrm{w}}\right]$} & {$\left[\boldsymbol{\%}_{\mathbf{w}}\right]$} & {$\left[\boldsymbol{\%}_{\mathbf{w}}\right]$} & {$\left[\boldsymbol{\%}_{\mathbf{w}}\right]$} & {$\left[\boldsymbol{\%}_{\mathrm{w}}\right]$} \\
\hline TI & 67 & 1.64 & 1.12 & 0.96 & 8.03 & 0.61 \\
\hline SFM320 & 34 & 2.90 & 2.40 & 1.40 & 13.04 & 10.20 \\
\hline SFM160 & 58 & 2.72 & 2.79 & 2.00 & 8.32 & 0.71 \\
\hline
\end{tabular}

${ }^{*} \%_{\mathrm{w}}=\mathrm{g} / 100 \mathrm{~g}$ of ash

The treatment of each oil fly ash sample with deionised water and hydrochloric acid resulted in two liquid phases and one solid phase, which amounted to 30-60\% of the original sample. Table 3 shows that the water treatment solubilises over $70 \%$ of the metallic content of TI and SFM160 and less than $25 \%$ of SFM320. Their solubility is reduced in the presence of magnesium oxide, which is used in power plants to neutralise $\mathrm{SO}_{3}$ (in SFM320). The high yields can be attributed to the presence of soluble sulphates of the metals [15]. The acidity of the ash decreases, leading to the formation of low soluble iron and nickel hydroxides [61].

Quantities of metal elements extracted by two-stage treatment of oil fly ashes with deionised water $\left(0.005 \mathrm{dm}^{3} / \mathrm{g}, T=\right.$ room, $\left.t=10 \mathrm{~min}\right)$ and with $2 \mathrm{M} \mathrm{HCl}\left(0.005 \mathrm{dm}^{3} / \mathrm{g}, T=90{ }^{\circ} \mathrm{C}, t=1 \mathrm{~h}\right)$

\begin{tabular}{|c|c|c|c|c|}
\hline \multirow{2}{*}{ Sample } & \multirow[t]{2}{*}{ Metal element } & \multicolumn{3}{|c|}{ Extracted quantities } \\
\hline & & in $\mathrm{H}_{2} \mathrm{O}^{*}$ & in $\mathrm{HCl}^{*}$ & in $\mathrm{H}_{2} \mathrm{O}+\mathrm{HCl}^{*}$ \\
\hline \multirow{4}{*}{ TI } & $\mathrm{V}$ & 1.31 & 0.30 & 1.61 \\
\hline & $\mathrm{Fe}$ & 0.85 & 0.15 & 1.00 \\
\hline & $\mathrm{Ni}$ & 0.67 & 0.22 & 0.89 \\
\hline & $\mathrm{Mg}$ & 0.45 & 0.15 & 0.59 \\
\hline \multirow{4}{*}{ SFM320 } & $\mathrm{V}$ & 0.23 & 2.62 & 2.85 \\
\hline & $\mathrm{Fe}$ & 0.12 & 2.04 & 2.16 \\
\hline & $\mathrm{Ni}$ & 0.35 & 0.88 & 1.23 \\
\hline & $\mathrm{Mg}$ & 6,85 & 3.25 & 10.10 \\
\hline \multirow{4}{*}{ SFM160 } & $\mathrm{V}$ & 2.25 & 0.40 & 2.65 \\
\hline & $\mathrm{Fe}$ & 1.95 & 0.67 & 2.62 \\
\hline & $\mathrm{Ni}$ & 1.40 & 0.30 & 1.70 \\
\hline & $\mathrm{Mg}$ & 0.55 & 0.15 & 0.70 \\
\hline
\end{tabular}

" $\mathrm{g} / 100 \mathrm{~g}$ of ash 
The elementary composition of the solid phase is given in Table 4. The obtained solid residue mainly consists of carbon containing less than $3 \%$ metal elements and sulphur. The solubilisation of the mineral fraction was almost complete and caused an increased porosity on the carbonaceous residue, as evidenced by the physical characterisation. The results of pore size and specific BET surface area are shown in Table 5 and can be summarised as follows:

1. the specific surface area increased more than four times for the WA-TI samples and about two times for the other two residues;

2. the pore volume increased four to five times in all WA residues compared with untreated ashes;

3. the average pore diameter reduced more than $25 \%$.

Table 4

Elementary chemical composition of the solid residues after the leaching treatments (weighted percentage of the dried sample $\left[\%_{\mathrm{w}}\right]^{*}$ )

\begin{tabular}{|c|c|c|c|c|c|c|}
\hline \multirow{2}{*}{ Sample } & $\mathbf{C}_{\text {unburnt }}$ & $\mathbf{V}$ & $\mathbf{F e}$ & $\mathbf{N i}$ & $\mathbf{S}$ & $\mathbf{M g}$ \\
\cline { 2 - 7 } & {$\left[\boldsymbol{\%}_{\mathbf{w}}\right]$} & {$\left[\boldsymbol{\%}_{\mathbf{w}}\right]$} & {$\left[\%_{\mathbf{w}}\right]$} & {$\left[\%_{\mathbf{w}}\right]$} & {$\left[\%_{\mathbf{w}}\right]$} & {$\left[\%_{\mathbf{w}}\right]$} \\
\hline TI & 97.3 & 0.04 & 0.17 & 0.10 & 0.03 & 0.03 \\
\hline SFM320 & 96.4 & 0.13 & 0.66 & 0.47 & 0.28 & 0.05 \\
\hline SFM160 & 97.8 & 0.11 & 0.28 & 0.50 & 0.16 & 0.04 \\
\hline
\end{tabular}

${ }^{*} \%_{\mathrm{w}}=\mathrm{g} / 100 \mathrm{~g}$ of ash

BET surface area (BET area), cumulative volume $(\mathrm{Vol})$, and average diameter of pores $(A D)$ :

Table 5 (a) before and (b) after the leaching treatments

\begin{tabular}{|c|c|c|c|c|c|c|}
\hline \multirow{2}{*}{ Sample } & \multicolumn{2}{|c|}{ BET area $\left[\mathrm{m}^{2} / \mathbf{g}\right]$} & \multicolumn{2}{|c|}{ Vol $\left[\mathrm{cm}^{3} / \mathbf{g}\right]$} & \multicolumn{2}{c|}{$\boldsymbol{A D}[\mathbf{A}]$} \\
\cline { 2 - 7 } & $\mathbf{( a )}$ & $\mathbf{( b )}$ & (a) & (b) & (a) & (b) \\
\hline TI & 11.5 & 63.5 & 0.02 & 0.08 & 105.3 & 54.9 \\
\hline SFM320 & 9.7 & 17.1 & 0.01 & 0.04 & 108.5 & 80.4 \\
\hline SFM160 & 10.3 & 26.9 & 0.01 & 0.05 & 107.9 & 74.8 \\
\hline
\end{tabular}

The increased porosity of the residues after the treatments justifies the rise on the adsorption of elements other than the solubilised mineral components. The different behaviour of the TI samples with respect to the other ones might be related to its slightly higher mineral content after the leaching treatment, which reduces the number of adsorbent sites accessible to the adsorbate. The greater specific surface area of the TI sample (more than twofold) compared to the other two residues also corroborates the above explanation for the different behaviours of the WA samples.

The specific adsorption capacities of the WA adsorbents, investigated in this study, are at least four times lower than that of commercially available active carbon used for adsorption. Therefore, greater quantities of WA are required (compared to active carbon) to remove the same amount of dye from wastewater. Nevertheless, the costs of materials are significantly lower than those entailed by the use of active carbon.

\section{Conclusion}

The double treatment of oil fly ash with deionised water and hydrochloric acid allows for the extraction of over $85 \%$ of the vanadium, iron, and nickel content in the ash. The residue derived from these treatments has a high content of unburnt carbon and 
presents a specific surface area that is approximately two to four times greater than that of untreated samples. The residue also has an MB adsorption capacity from 6 to $40 \mathrm{mg} / \mathrm{g}$ for solutions of 200 to $1000 \mathrm{mg} / \mathrm{dm}$. The maximum amount of dye was adsorbed after one hour. High abatement efficiencies (> $99 \%$ ) can be obtained through contact of 1 to $3 \mathrm{~g}$ of carbonaceous residue with $0.050 \mathrm{dm}^{-3}$ of $\mathrm{MB}$ in the same concentration. The adsorbed material is released almost immediately when the residues are re-contacted with water, thus allowing for the regeneration of the adsorbent.

Results show that the Langmuir isotherm model is in good agreement with the equilibrium data, indicating a maximum monolayer saturation capacity of approximately $40 \mathrm{mg} / \mathrm{g}$ at $25^{\circ} \mathrm{C}$. The adsorption capacity of the samples used in this study were at least four times lower than those of the commercially available active carbons, which are commonly used for adsorption purposes. However, the negligible or zero cost of these solid residues, otherwise disposed in landfills, suggest that their use is a potential alternative to limit their landfilling.

\section{References}

[1] EU Council. Official J European Union. 2008;L312/3. https://eur-lex.europa.eu/legal-content/ EN/TXT/HTML/?uri=CELEX:32008L0098\&from=EN.

[2] Aslam Z, Shawabkeh RA, Hussein IA, Al-Baghli N, Eic M. Appl Surf Sci. 2015;327:107-15. DOI: 10.1016/j.apsusc.2014.11.152.

[3] Li X, Miao W, Lv Y, Wang Y, Gao C, Jiang D. Thermochim Acta. 2018;666:1-9. DOI: 10.1016/j.tca.2018.05.023.

[4] Salah N, Alshahrie A, Abdel-Wahaba M, Alharbic ND, Khan ZH. Diam Relat Mat. 2017;78:97-104. DOI: 10.1039/C7RA07155H.

[5] Silvestre-Albero J, Rodríguez-Reinoso F. Novel Carbon Adsorbents. 1st ed. Oviedo: Elsevier Store; 2011; 583-603. ISBN: 9780080977447

[6] Pandey B, Kinrade SD, Catalan LJ. J Environ Manage. 2012;101:59-67. DOI: 10.1016/j.jenvman.2012.01.029.

[7] Montalvo S, Cahn I, Borja R, Huiliñir C, Guerrero L. Bioresour Technol. 2017;244:416-22. DOI: 10.1016/j.biortech.2017.07.159.

[8] Eliche-Quesada D, Sandalio-Pérez JA, Martínez-Martínez S, Pérez-Villarejo L, Sánchez-Soto PJ. Ceram Int. 2017;44:4400-12. DOI: 10.1016/j.ceramint.2017.12.039.

[9] Al-Ghouti MA, Al-Degs YS, Ghrair A, Khoury H, Ziedan M. Chem Eng J. 2011;173:191-7. DOI: 10.1016/j.cej.2011.07.080.

[10] Akita S, Maeda T, Takeuchi H. J Chem Technol Biot. 1995;62:345-50. DOI: 10.1002/jctb.280620406.

[11] Primerano P, Catalfamo P, Di Pasquale S, Corigliano F. New methods for the production of pure vanadium pentoxide or a ferrovanadium concentrate from oil residues. In: Recycling and Reuse of Waste Materials. Dhir RK, Newlands MD, Halliday JL, editors. London: Thomas Telford Publishing; 2003; 287-295. ISBN: 0727732528.

[12] Vitolo S, Seggiani M, Filippi S, Brocchini C. Hydrometallurgy. 2000;57:141-9. DOI: 10.1016/S0304-386X(00)00099-2.

[13] Al-Degs YS, Ghrir A, Khoury H, Walker GM, Sunjuk M, Al-Ghouti MA. Fuel Process Technol. 2014;123:41-6. DOI: 10.1016/j.fuproc.2014.01.040.

[14] Alonso-Hernández CM, Bernal-Castillo J, Bolanos-Alvarez Y, Gómez-Batista M, Diaz-Asencio M. Fuel. 2011;90:2820-3. DOI: 10.1016/j.fuel.2011.03.014.

[15] Primerano P, Di Pasquale S, Mavilia L, Corigliano F. Atmos Environ. 1998;32:225-30. DOI: 10.1016/S1352-2310(97)00243-4.

[16] Hsieh YM, Tsai MS. Carbon. 2003;41:2317-24. DOI: 10.1016/S0008-6223(03)00283-5.

[17] Cavallaro G, Gianguzza A, Lazzara G, Milioto S, Piazzese D. Appl Clay Sci. 2013;72:132-7. DOI: 10.1016/j.clay.2012.12.001.

[18] Cataldo S, Cavallaro G, Gianguzza A, Lazzara G, Pettignano A, Piazzese D, et al. J. Environ Chem Eng. 2013;1:1252-60. DOI: 10.1016/j.jece.2013.09.012.

[19] Cataldo S, Gianguzza A, Merli M, Muratore N, Piazzese D, Liveri ML. Colloid Interface Sci. 2014;434:77-88. DOI: 10.1016/j.jcis.2014.07.042. 
[20] Piazzese D, Cataldo S, Muratore N. Int J Electrochem Sci. 2015;10:7423-39. http://www.electrochemsci.org/papers/vol10/100907423.pdf.

[21] Adegoke KA, Bello OS. Water Res Ind. 2015;12:8-24. DOI: 10.1016/j.wri.2015.09.002.

[22] Ali I, Peng C, Khan Z, Sultan M, Naz I. Arab J Sci Eng. 2018;43(11):6245-59. DOI: 10.1007/s13369-018-3441-6.

[23] Ali I, Peng C, Liun D, Naz I. Green Process Synth. 2019;8(1):256-71. DOI: 10.1515/gps-2018-0078.

[24] Dai Y, Sun Q, Wang W, Lu L, Liu M, Li J, et al. Chemosphere. 2018;211:235-53. DOI: 10.1016/j.chemosphere.2018.06.179.

[25] Mo J, Yang Q, Zhang N, Zhang W, Zheng Y, Zhang Z. J Environ Manage. 2018;227:395-405. DOI: 10.1016/j.jenvman.2018.08.069.

[26] Swan NB, Zaini MAA. Ecol Chem Eng S. 2019;26(1):119-32. DOI: 10.1515/eces-2019-0009.

[27] Makuchowska-Fryc J. Ecol Chem Eng S. 2019;26(1):165-74. DOI: 10.1515/eces-2019-0012.

[28] Andini S, Cioffi R, Colangelo F, Montagnaro F, Santoro L. J Hazard Mater. 2008;157:599-604. DOI: 10.1016/j.jhazmat.2008.01.025

[29] Banerjee SS, Jayaram R., Joshi MV. Sep Sci Technol. 2003;38:1015-32. DOI: 10.1081/SS-120018121.

[30] Çalışkan Y, Harbeck S, Bektaş N. Environ Prog Sustain. 2018;38(S1):S185-95. DOI: 10.1002/ep.12969.

[31] Caramuscio P, De Stefano L, Seggiani M, Vitolo S, Narducci P. Waste Manage. 2003;23:345-51. DOI: 10.1016/S0956-053X(02)00118-6.

[32] Davini P. Carbon. 2003;41:1559-65. DOI: 10.1016/S0008-6223(03)00104-0.

[33] Janos P, Buchtova H, Ryznarova M. Water Res. 2003;37:4938-44. DOI: 10.1016/j.watres.2003.08.011.

[34] Rafatullah M, Sulaiman O, Hashim R, Ahmad A. J Hazard Mater. 2010;177:70-80. DOI: 10.1016/j.jhazmat.2009.12.047.

[35] Raman CD, Kanmani S. Environ Prog Sustain. 2018;38(S1):S366-76. DOI: 10.1002/ep.13063.

[36] Rathnayake M, Julnipitawong P, Tangtermsirikul S, Toochinda P. J Clean Prod. 2018;202:934-45. DOI: 10.1016/j.jclepro.2018.08.204.

[37] Avom J, Ketcha J, Noubactep C, Germain P. Carbon. 1997;35:365-9. DOI: 10.1016/S0008-6223(96)00158-3.

[38] Hameed BHD, Ahmad TM, Ahmad AL. J Hazard Mater. 2007;141:819-25. DOI: 10.1016/j.jhazmat.2006.07.049.

[39] Senthilkumaar S, Varadarajan PR, Porkodi K, Subbhuraam CV. J Colloid Interf Sci. 2005;284:78-82. DOI: 10.1016/j.jcis.2004.09.027.

[40] Wu XL, Shi Y, Zhong S, Lin H, Chen JR. Appl Surf Sci. 2016;378:80-6. DOI: 10.1016/j.apsusc.2016.03.226.

[41] Vakili M, Rafatullah M, Salamatinia B, Abdullah AZ, Ibrahim MH, Tan KB, et al. Carbohyd Polym. 2014;113:115-30. DOI: 10.1016/j.carbpol.2014.07.007.

[42] Ahmad A, Mohd-Setapar SH, Chuong CS, Khatoon A, Wani WA, Kumar R, et al. RSC Adv. 2015;39:30801-18. DOI: 10.1039/c4ra16959j.

[43] Ahmad T, Danish M, Rafatullah M, Ghazali A, Sulaiman O, Hashim R, et al. Environ Sci Pollut. Res. 2012;19:1464-84. DOI: 10.1007/s11356-011-0709-8.

[44] Ahmad T, Rafatullah M, Ghazali A, Sulaiman O, Hashim R. J Environ Sci Health C. 2011;29(3):177-222. DOI: 10.1080/10590501.2011.601847.

[45] Low LW, Teng TT, Rafatullah M, Morad N, Azahari B. Sep Sci Technol. 2013;48(11):1688-98. DOI: 10.1080/01496395.2012.756912.

[46] Cusack PB, Healy MG, Ryan PC, Burke IT, O' Donoghue LMT, Ujaczki E, et al. J Clean Prod. 2018;179:217-24. DOI: 10.1016/j.jclepro.2018.01.092.

[47] Palazzi E, Currò F, Fabiano B. Proc Saf Environ. 2015;97:37-48. DOI: 10.1016/j.psep.2015.06.009

[48] Saidani M, Bernard B, Leroy Y, Cluzel F, Kendall A. J Clean Prod. 2019;207:542-59. DOI: 10.1016/j.jclepro.2018.10.014.

[49] Suresh Kumar P, Ejerssa WW, Wegener CC, Korving L, Dugulan AI, Temmink H, et al. Water Res. 2018;145:365-74. DOI: 10.1016/j.watres.2018.08.040.

[50] Jawad AH, Razuan R, Appaturi JN, Wilson LD. Surfaces Interfaces. 2019;16:76-84. DOI: 10.1016/j.surfin.2019.04.012.

[51] Labaran BA, Vohra MS. Desalin Water Treat. 2016;57(34):16034-52. DOI: 10.1080/19443994.2015.1074118.

[52] Ozbay N, Yargic AS. J Clean Prod. 2015;100:333-43. DOI: 10.1016/j.jclepro.2015.03.050.

[53] Chingono KE, Sanganyadob E, Bere E, Yalala B. J Environ Manage. 2018;224:182-90. DOI: 10.1016/j.jenvman.2018.07.042.

[54] El-Bindary AA, El-Sonbati AZ, Al-Sarawy AA, Mohamed KS, Farid MA. J Mol Liq. 2014;199:71-8. DOI: 10.1016/j.molliq.2014.08.010. 
[55] Guendy HR. J Appl Sci Res. 2010;6(8):964-72. www.aensiweb.com/old/jasr/jasr/2010/964-972.pdf.

[56] Kiran I, Akar T, Ozcan AS, Ozcan A, Tunali S. Biochem Eng J. 2006;31:197-203. DOI: 10.1016/j.bej.2006.07.008.

[57] Langmuir I. J Am Chem Soc. 1918;40(9):1361-403. DOI: 10.1021/ja02242a004. https://pubs.acs.org/doi/10.1021/ja02242a004.

[58] Freundlich HMF. J Phys Chem. 1906;57:385-471. DOI: 10.1515/zpch-1907-5723. https://www.degruyter.com/view/j/zpch.1907.57.issue-1/zpch-1907-5723/zpch-1907-5723.xml.

[59] Yamada K, Haraguchi K, Gacho CC, Bussakorn PW, Pena ML. Removal of dyes from aqueous solution by sorption with coal fly ash. In: Proceedings of International Ash Utilization Symposium. Centre for Applied Energy Research. University of Kentucky; 2003:1-6. www.p2infohouse.org/ref/45/44848.pdf.

[60] Gupta VK, Mohan D, Sharma S, Sharma M. Sep Sci Technol. 2000;35:2097-113. DOI: 10.1081/SS-100102091.

[61] Primerano P, Campisi I, Di Pasquale S, Corigliano F. Atmos Environ. 1999;33:3551-8. DOI: $10.1016 / \mathrm{S} 1352-2310(99) 00111-9$. 